\title{
How elemental composition influences the color of igneous and sedimentary rocks: Case of the High Atlas rocks of Morocco
}

\author{
Mouhssin El Halim ${ }^{1,2}$ () \\ Lahcen Daoudi ${ }^{1}$ \\ Abdelhafid El Alaoui El Fels ${ }^{1}$ ()
}

${ }^{1}$ Laboratoire des Géo-ressources, Géoenvironnement et Génie civil (L3G), Département de Géologie, Faculté des Sciences et Techniques, Université Cadi Ayyad, Marrakech, Morocco

${ }^{2}$ Laboratoire des Argiles, Géochimie et Environnements Sédimentaires (AGEs), Département de Géologie, Université de Liège, Liège, Belgium

\section{Correspondence}

Mouhssin El Halim, Laboratoire des Géoressources, Géo-environnement et Génie civil (L3G), Département de Géologie, Faculté des Sciences et Techniques, Université Cadi Ayyad,

BP 549 Marrakech, Morocco.

Email: elhalim.mouhsin@gmail.com

\section{Funding information}

Bilateral Cooperation Project Wallonie Bruxelles Maroc, Grant/Award Number: 2.7; PPR-CNRST Program, Grant/Award Number: PPR1/2015/63; Erasmus Plus

\begin{abstract}
In spite of color being one of the physicochemical parameters most commonly used to characterize a rock, very limited studies have studied the correlation between the nature, chemical composition, and color of a rock. This study presents a new approach for quantitatively assessing the relationship between these three parameters for specific rocks (example of igneous and sedimentary rocks) collected from the High Atlas of Morocco. A spectrophotometer was used to measure the color of samples, and the measurements were expressed in CIE L*a*b* color system units then converted to Hex color codes. Whereas, the chemical composition of samples was carried out by X-ray fluorescence. The most abundant oxides in magmatic rock samples are $\mathrm{SiO}_{2}, \mathrm{Al}_{2} \mathrm{O}_{3}, \mathrm{Fe}_{2} \mathrm{O}_{3}$, $\mathrm{MgO}$, and $\mathrm{CaO}$, while $\mathrm{K}_{2} \mathrm{O}, \mathrm{Na}_{2} \mathrm{O}$, $\mathrm{TiO}_{2}$, and $\mathrm{P}_{2} \mathrm{O}_{5}$ are generally found in trace concentrations. Two categories of clays were studied, non-calcareous raw materials without carbonate contents $(<4 \% \mathrm{CaO})$ and calcareous clays or marls $(\mathrm{CaO}>10 \%)$. Phosphate samples are rich in phosphorus $(4.4 \%-17.5 \%)$ and $\mathrm{CaO}(11.2 \%-42.7 \%)$ with relatively low contents of $\mathrm{SiO}_{2}$ (28.5\%-52.2\%), $\mathrm{Al}_{2} \mathrm{O}_{3}$ (3.1\%-17.5\%), and $\mathrm{Fe}_{2} \mathrm{O}_{3}$ (1.1\%-6.6\%). Results show that the change in the content of these elements from one rock type to another may be indicative of rocks with particular characteristics that do have an impact on color. The main coloration agent of clays was iron, $\mathrm{Fe}^{2+}$, and $\mathrm{Fe}^{3+}$ ions can color clay minerals either red or green or in various shades of orange and brown. However, in marls and phosphates, the high concentration of carbonates inhibits this iron effect by affecting $\mathrm{a}^{*}$ (red) and $\mathrm{b}^{*}$ (yellow) color parameters, which leads to grayish materials. The same applies to magmatic rocks rich in $\mathrm{Fe}_{2} \mathrm{O}_{3}$ and $\mathrm{CaO}$.
\end{abstract}

\section{KE Y W O R D S}

chemical composition, cluster analysis, color parameters, principal component analysis, spectrophotometric analysis

\section{1 | INTRODUCTION}

The igneous rocks are the first materials that formed the earth's crust, ${ }^{1}$ these rocks are mainly derived from the fusion by decompression and/or wet fusion of protolithic lithologies that occur in the deep layers of the earth. Sedimentary rocks result from the accumulation of sediments deposited most often in layers or superposed beds, known 
as strata, they are formed by the accretion of diverse sediments, that is, solid elements (clasts, shells debris, etc.) and/or precipitations of solutions ${ }^{2}$ (which come from cement, often intercalated between grains, particles, or clasts). Their classifications and compositional, petrographic, and textural characteristics are well-studied.

There are several ways to classify and differentiate between magmatic and sedimentary rocks, based mainly on the chemical, mineralogical, and textural composition of each type. However, very limited work has been done to study the link between the color of a rock, the origin, and the chemical composition. ${ }^{3}$ Such a study is particularly important to facilitate the identification of a rock from its color and also to have an indication about the elemental composition before performing chemical analysis. Indeed, several studies have been done to establish the relationship between the mineralogy and the color of rocks, ${ }^{4-7}$ other recent studies have explored the effect of the particle size distribution on the colour of sedimentary rocks. ${ }^{8}$ However, the link between chemical composition and color is not well studied.

It has been known for some time that relationships exist between the color, physical, and chemical characteristics of materials. ${ }^{9-12}$ Different elements and compounds of those elements exhibit different colors and when present in sufficient concentrations can influence the overall color of a geological sample. Examples of colors associated with elements in minerals include: vanadium (red/green/purple depending on the compound involved); chromium (blue-green); manganese (dark red, green, or blue); iron (red/blue depending on the ionic form taken); cobalt (red/blue); nickel (green/blue/purple); copper (blue/green); zinc (pale blue); and lead (yellow). However, the concentration of these elements is unlikely to be sufficiently high in geological materials like clays, magmatic rocks, phosphates, and marls to actually contribute to the overall color of these materials, which will be dominated by major oxides $\left(\mathrm{SiO}_{2}, \mathrm{~K}_{2} \mathrm{O}, \mathrm{Al}_{2} \mathrm{O}_{3}, \mathrm{Fe}_{2} \mathrm{O}_{3}, \mathrm{MgO}\right.$, $\mathrm{CaO}$, and $\mathrm{P}_{2} \mathrm{O}_{5}$ ).

This is the context for which the present study is conducted; it presents a new approach to assess the relationship between the origin, color, and chemical composition of rocks quantitatively. The aim is to explore the correlation between these three parameters through a statistical study based on principal component analysis (PCA), hierarchical classification, and other statistical methods combined with the results of chemical and spectrophotometric analysis.

\section{2 | MATERIALS AND METHODS}

The studied samples include 27 geological materials with different chemical compositions and colors. Thirteen samples belong to the magmatic rock group (MR 1 to 22), 10 are clay deposits ( $\mathrm{Cl} 1$ to 8 ) including 2 calcareous clay samples or marls (M1 and M2), and 4 phosphate rocks (P1 to P4). These materials were carefully ground and homogenized using a FRITSCH PULVERISETTE Planetary Mill, then sifted to $250 \mu \mathrm{m}$ to make the color and composition of samples evenly homogeneous (Figure 1). For the reason that in a powder material, the color is related to the grain size distribution and a simple change in the size of a powder can change the color.

X-ray fluorescence spectroscopy was used in diffuse mode over an area of $108 \mu \mathrm{m} \times 88 \mu \mathrm{m}$ on the surface of each sample to determine the chemical composition of major elements ( $\mathrm{Si}, \mathrm{K}, \mathrm{Al}, \mathrm{Fe}, \mathrm{Mg}, \mathrm{Ca}, \mathrm{Mn}, \mathrm{Ti}, \mathrm{Na}$, and $\mathrm{P}$ ), the XRF analyzer used is of the Epsilon $1 \mathrm{X}$-ray fluorescence analyzer type, with a Silicon photodiode array (dual 36-element) detector, available in the laboratory of Geosciences, Geo-resources and Civil Engineering, Cadi Ayyad University of Marrakech. Elemental composition was determined by non-destructive measurement, which makes the method a tempting tool for the investigation of a wide range of materials and particularly for archeological resources. Quantitative analysis was performed using Oxford Instruments (Fremont, California) standards of metals, synthetic compounds, and natural minerals. The contents represent the average of three to five measurements.

A portable spectrophotometer CM 700d type from Konica Minolta is set up in specular reflection included (SCI) or excluded (SCE) mode to determine the RGB (red, green, blue) parameters of all colors, available in Higher School of Fine Arts (ESA) of Liege. Wavelength range is between 400 and $700 \mathrm{~nm}$, with a Pulsed xenon lamp (with UV cut filter) as light source. Wavelength pitch and half bandwidth are around $10 \mathrm{~nm}$. The obtained RGB data are then converted to Hex color code and CIELab colour coordinate system through a combination of internet-based sources, many of which are relatively old and contain partial lookup tables. One of the most useful sources of information was a website developed by Boronkay, ${ }^{13}$ which supplies a Microsoft Excel spreadsheet containing a number of conversion utilities. Full lookup tables for all Munsell to RGB and Munsell to CIELab conversions are available from the authors on request. The data obtained were processed by the inspection and color control software SpectraMagic TM NX Pro.

The CIELAB system is since 1976, is a widely used system for calculating color differences for most practical applications. Use of the CIELAB system enables estimation of three classical color parameters: $L^{*}, a^{*}$, and $b^{*}$, where $L^{*}$ represents lightness, $a^{*}$ represents the position between red and green on the redness $(+)$ to greenness $(-)$ axis, and $\mathrm{b}^{*}$ represents the position between yellow and blue on the yellowness $(+)$ to blueness $(-)$ axis. ${ }^{11}$ 


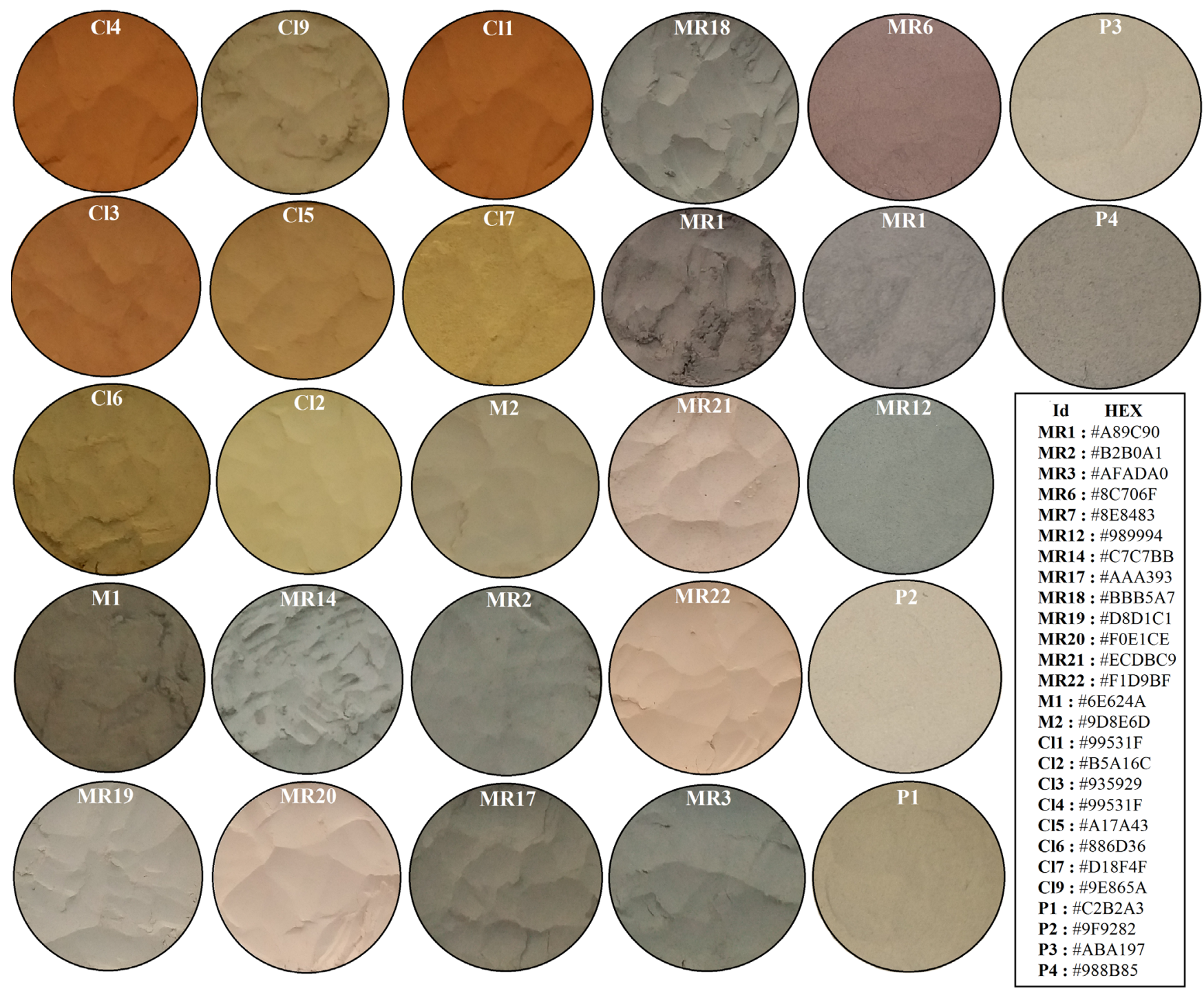

F I G U R E 1 List of studied samples after grinding and sieving. Cl, clays; M, marls; MR, magmatic rocks; P, phosphates

The statistical analysis and the visualization of results are served using the functions provided by the two packages FactoMineR and Factoextra under the $\mathrm{R}$ Software. The statistical methods used are the PCA and Hierarchical Classification on Main Components $(\mathrm{HCMC}){ }^{14}$

\section{3 | RESULTS}

\section{1 | Elemental composition of the studied samples}

Samples analyzed by X-ray fluorescence show a chemical composition that depends on the nature of the rock. Silica and aluminum are the most abundant elements with contents ranging from $27.2 \%$ to $87.7 \%$ for $\mathrm{SiO}_{2}$ and $3.1 \%$ to $26.9 \%$ for $\mathrm{Al}_{2} \mathrm{O}_{3}$ (Table 1). These two elements are less abundant in marls and phosphates.

Iron is present in moderate quantities in magmatic rocks (with the exception of MR20, 21, and 22), $\mathrm{Fe}_{2} \mathrm{O}_{3}$ content ranges from $5 \%$ to $20.4 \%$ in these materials. In clays and phosphates, the $\mathrm{Fe}_{2} \mathrm{O}_{3}$ content ranges between $1.1 \%$ and $10 \%$.

The carbonate content reaches $42.7 \%$ for the marl sample M2, and around $10.2 \%$ for $\mathrm{M} 1$. CaO is also present in large quantities in phosphates (between $11.2 \%$ and $42.7 \%$ ). The analyzed magmatic rocks contain a concentration between $1.8 \%$ and $8.6 \%$. Clay samples as well as MR20, MR21, and MR22 are devoid of CaO. However, maximum $\mathrm{MgO}$ levels are reached in samples MR18 (12\%) and M2 (17.1\%), other samples have values between $1 \%$ and $8.2 \%$, samples MR20, MR21, MR22, Cl2, $\mathrm{Cl} 4, \mathrm{Cl} 5$, and $\mathrm{Cl} 7$ contain less than $1 \%$. 


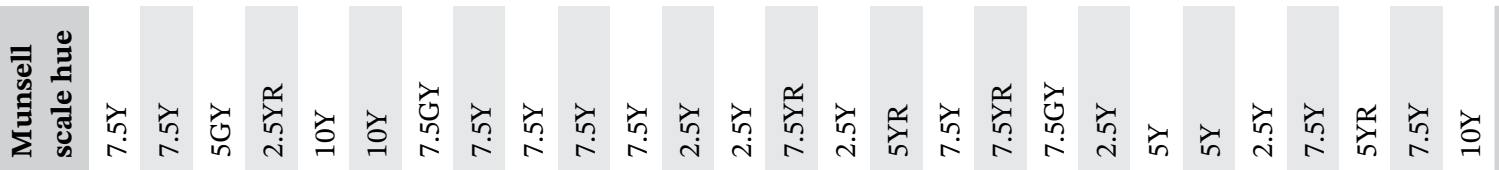

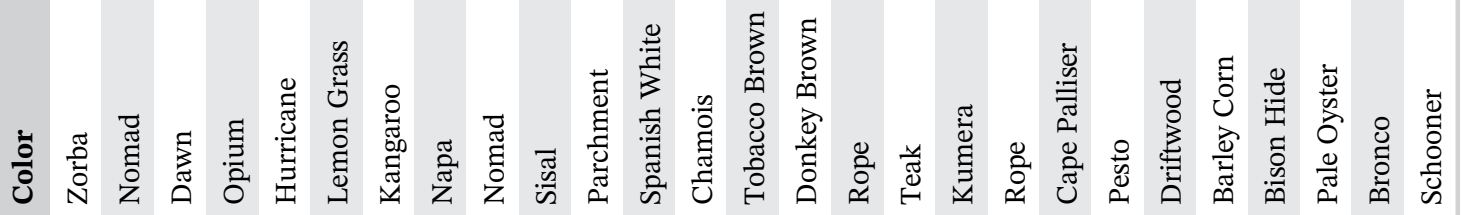

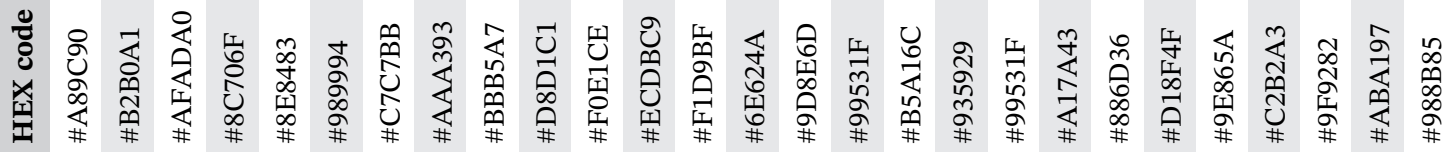

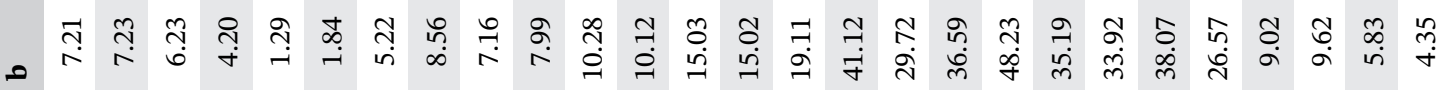

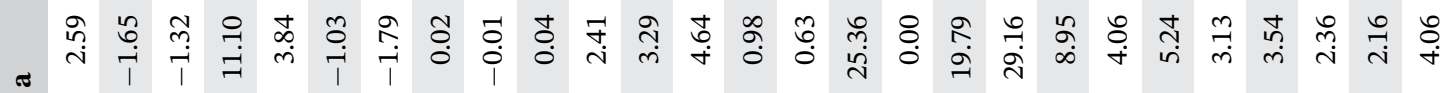
๘) \lrcorner मुं

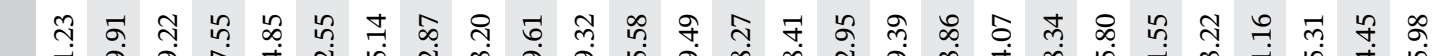

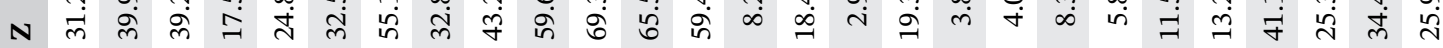

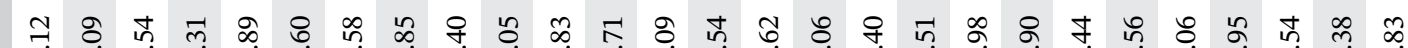

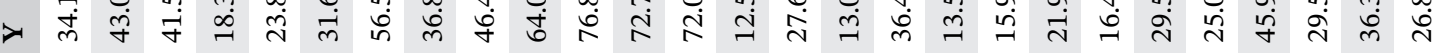

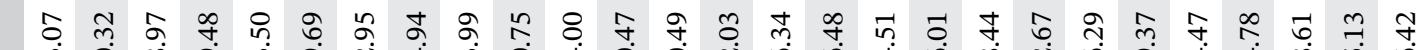
$x$ ल

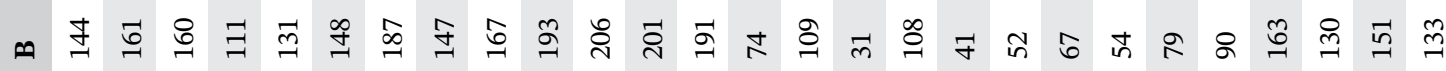
ט

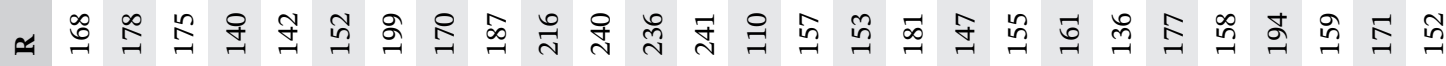
每 

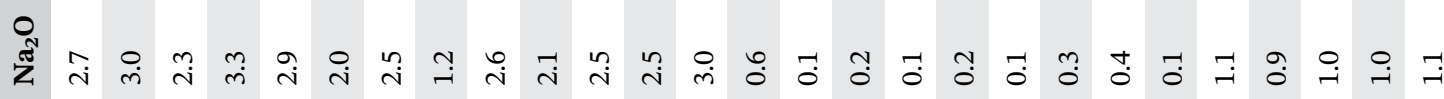
J

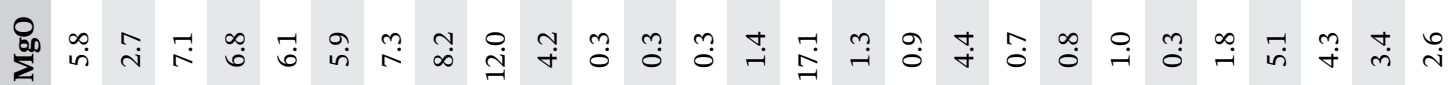

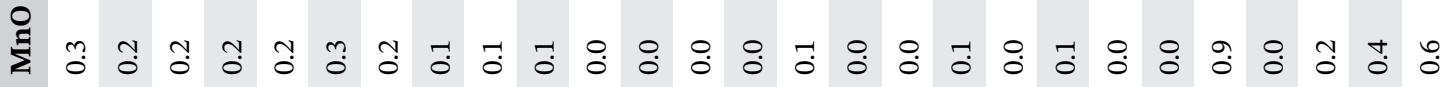

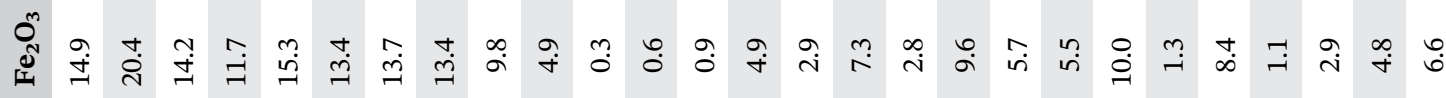

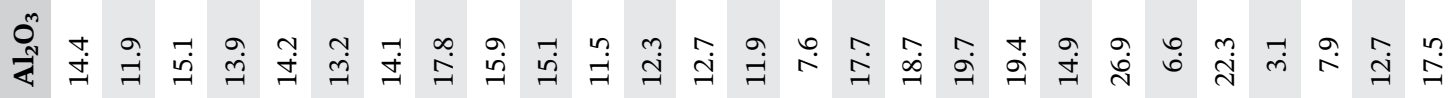

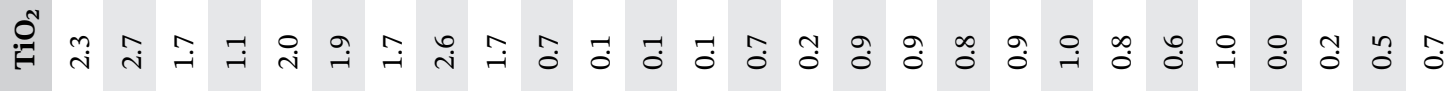

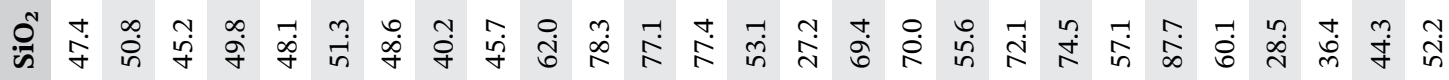



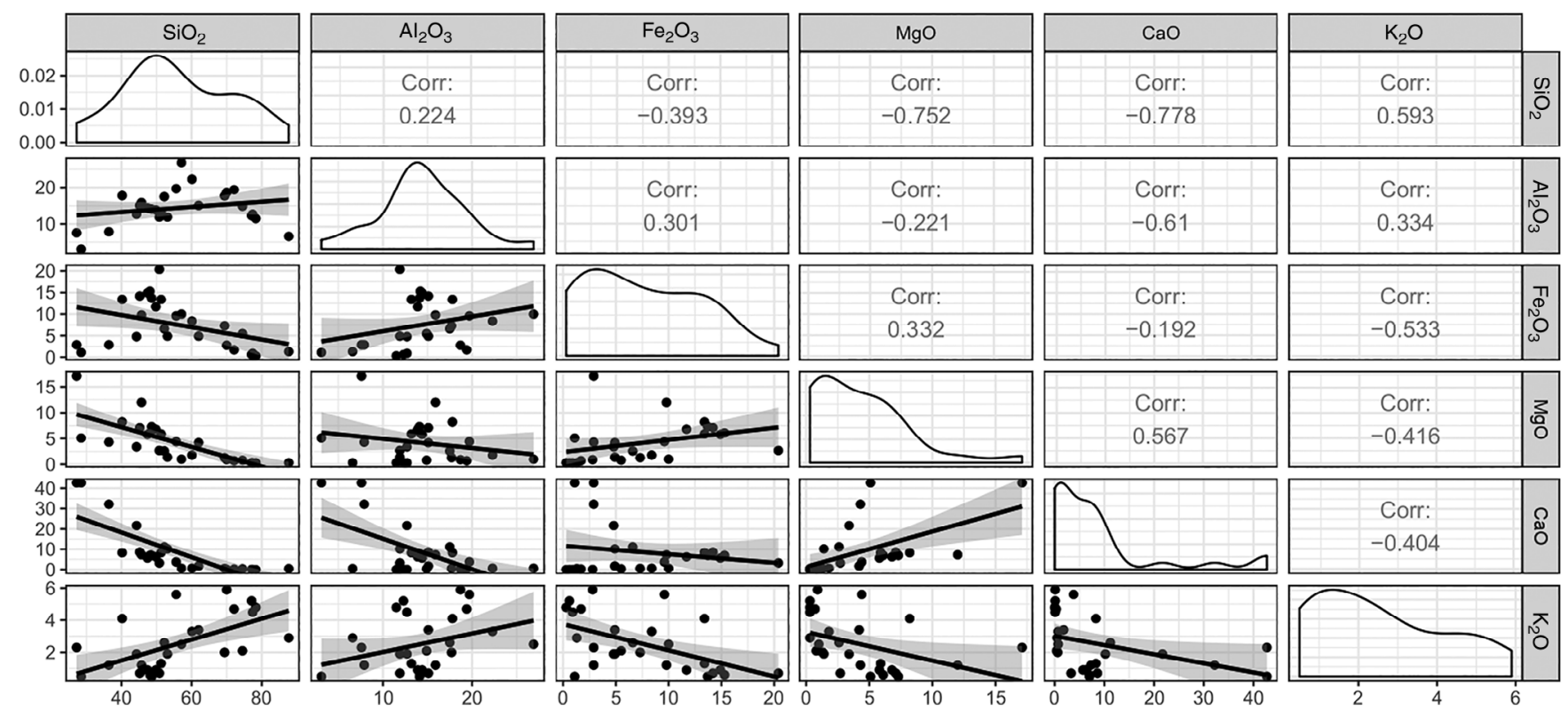

F I G U RE 2 Binary diagrams showing the degree of correlation between the main chemical elements components of studied samples

$\mathrm{TiO}_{2}, \mathrm{Na}_{2} \mathrm{O}$, and $\mathrm{K}_{2} \mathrm{O}$ are present in small quantities; their maximum values are in the order of $2.7 \%, 3.3 \%$, and $5.9 \%$ respectively, while $\mathrm{MnO}$ is present as trace.

The studied clays, marls, and magmatic rocks are devoid of $\mathrm{P}_{2} \mathrm{O}_{5}$; therefore it requires studying phosphate samples to determine how this element influences the color of a rock. The phosphorus content ranges from $4.4 \%$ in $\mathrm{P} 4$ to $17.5 \%$ in $\mathrm{P} 1$.

Binary diagrams of Figure 2 show that $\mathrm{CaO}$ and $\mathrm{MgO}$ are negatively correlated with silica and aluminum. Carbonate and magnesium-rich samples tend to have relatively low values of $\mathrm{SiO}_{2}$ and $\mathrm{Al}_{2} \mathrm{O}_{3}$, while the other elements have no significant correlation.

\section{2 | Determination of sample color parameters}

Magmatic rocks especially MR19, MR20, MR21, and MR22 have RGB values slightly higher than the other materials, whereas $\mathrm{Cl} 1, \mathrm{Cl} 3, \mathrm{Cl} 4, \mathrm{Cl} 6$, and $\mathrm{Cl} 7$ have the lowest values. Coordinates $\mathrm{X}, \mathrm{Y}$, and $\mathrm{Z}$ also show changes, expressing the transition from a light to a dark color. The three CIELAB coordinates ${ }^{15}$ indicate the lightness of the color $\left(\mathrm{L}^{*}=0\right.$ gives black and $\mathrm{L}^{*}=100$ refers to diffuse white; specular white may be higher), its location ranges between red and green $\left(a^{*}\right.$, where negative values indicate green and positive values represent red) and its location between yellow and blue ( $b^{*}$, where negative values indicate blue and positive values indicate yellow).

The color of the analyzed magmatic rocks varies from parchment color (Hex code $=$ \#F0E1CE) to opium (Hex code $=\# 8 \mathrm{C} 706 \mathrm{~F})$. Clays have in general an orange to brown color. Marls M1 and M2 have a Tobacco and Donkey brown color (Hex codes = \#6E624A and \#9D8E6D respectively), while the phosphates have a color that tends to gray.

\section{3 | Chemical composition in relation with the color of samples}

PCA of the chemical elements shows three groups (Figure 3): the first one includes MR samples (excluding MR19, 20, 21, and 22), these samples are relatively rich in iron (9.8\%-20.4\% of $\mathrm{Fe}_{2} \mathrm{O}_{3}$ ), magnesium $(2.7 \%-12 \%$ of $\mathrm{MgO}$ ), sodium ( $1.2 \%-3.3 \%$ of $\mathrm{Na}_{2} \mathrm{O}$ ), and titanium dioxide (1.1\%-2.7\% of $\mathrm{TiO}_{2}$ ). The contents of $\mathrm{SiO}_{2}, \mathrm{Al}_{2} \mathrm{O}_{3}, \mathrm{~K}_{2} \mathrm{O}$, and $\mathrm{CaO}$ in these samples range from $40.2 \%$ to $51.3 \%, 11.9 \%$ to $17.8 \%, 0.5$ to $1.3 \%$ and $3.3 \%$ to $8.6 \%$ respectively. The RGB values for this group of samples are between 140 to 199 for red, 112 to 199 for green, and 111 to 187 for blue.

The second group includes clay samples rich in silica and aluminum (68.3\% $\mathrm{SiO}_{2}$ and $17.7 \% \mathrm{Al}_{2} \mathrm{O}_{3}$ on average) with moderate iron contents $\left(6.1 \% \mathrm{Fe}_{2} \mathrm{O}_{3}\right.$ on average). The samples MR19, MR20, MR21, and MR22 have joined this group due to their chemical characteristics close to those of clays. This group also has high values of $\mathrm{K}_{2} \mathrm{O}$ (3.7\% on average), but is generally devoided of $\mathrm{CaO}$, $\mathrm{TiO}_{2}$, and $\mathrm{MgO}$. Magmatic rock samples included in this group (MR 19 to 22) have the highest RGB values (between 193 and 241) while clays have the lowest values especially for green and blue. The last group contains the phosphate samples, RGB values vary from 152, 139, and 


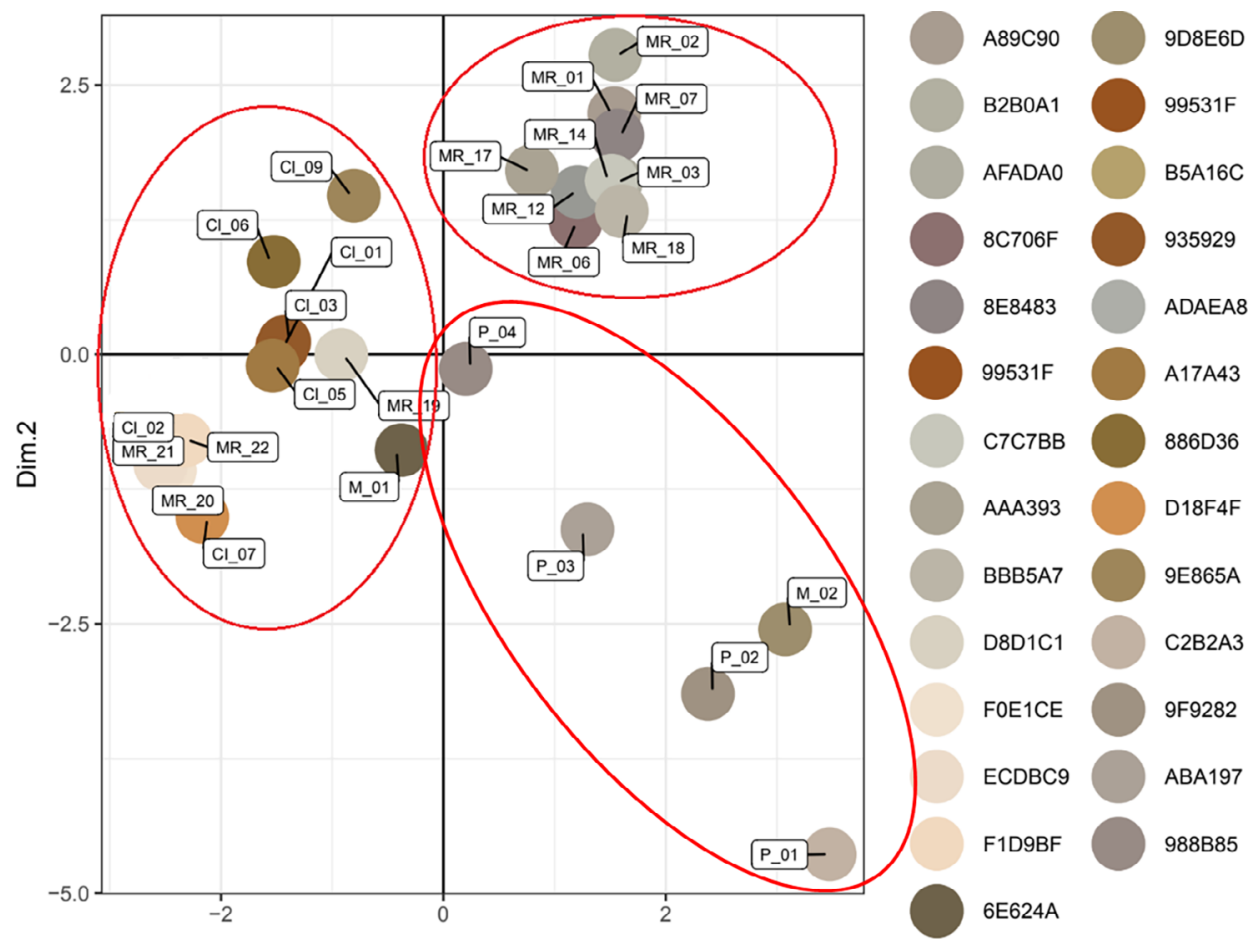

FIGURE 3 Principal component analysis (PCA) of chemical elements according to the color of samples
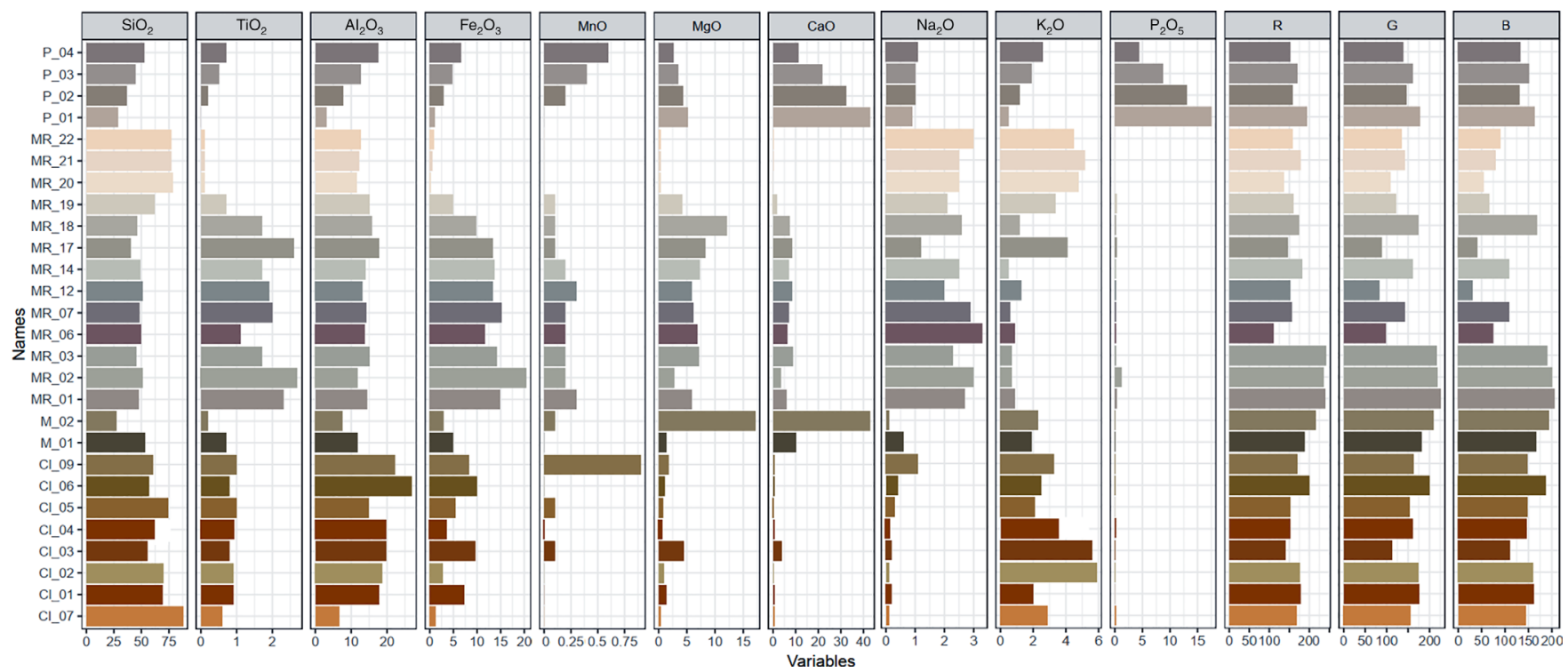

F I G U RE 4 Evolution of chemical elements and color parameters (RGB, L*a*b) in the studied samples

133 for P4 enriched in silica (52.2\%), aluminum (17.5\%), and iron (6.6\%). Whereas P1 sample, rich in phosphorus (17.5\%) and $\mathrm{CaO}(42.7 \%)$ with low contents of $\mathrm{SiO}_{2}$ (28.5\%), $\mathrm{Al}_{2} \mathrm{O}_{3}$ (3.1\%), and $\mathrm{Fe}_{2} \mathrm{O}_{3}$ (1.1\%), shows RBG values of 194,178 , and 163 .

The results show that $L^{*}, a, b^{*}$ parameters are sensitive to the variation of chemical elements from one sample to another. The $\mathrm{L}^{*}$ coordinate displays an increase values in samples rich of silica and aluminum without iron, calcium oxide, and phosphorus (MR19, MR20, and MR21), these samples have also the higher RGB values and their color tends to the Off-White Color collection (Figure 4). The other magmatic rock samples have the values close to 0 in the $a^{*}$ and $b^{*}$ coordinates, which makes their colors in shades of gray. Phosphates show a darker gray colour depending on the concentration of $\mathrm{P}_{2} \mathrm{O}_{5}$ and $\mathrm{CaO}$, the $\mathrm{a}^{*}$ and $\mathrm{b}^{*}$ coordinate values vary in these samples between 2 to 4 and 4 to 9 respectively. 
Clay samples exhibit larger color changes, always involving an increase in $a^{*}$ and $b^{*}$ parameters except for $\mathrm{Cl} 2$ sample. The chemical composition of clays (high silica and aluminum content with moderate iron and without carbonates) makes these materials appear as brown to orange color.

The chemical composition of marls is similar to clays with high $\mathrm{CaO}$ concentrations (10\% for $\mathrm{M} 1$ and $42 \%$ for M2), this variation in carbonate contents leads to a decrease in $\mathrm{a}^{*}$ and $\mathrm{b}^{*}$ values that shift the color of these materials to gray. Negative values for $\mathrm{a}^{*}$ coordinate (red-green) are obtained, they are correlated with high levels of iron $\left(\mathrm{Fe}_{2} \mathrm{O}_{3}>13 \%\right)$ in samples MR2, MR3, MR12, and MR14.

\section{4 | DISCUSSION}

Many of the studied chemical elements could display a range of colours in materials, depending upon conditions such as redox potential and $\mathrm{pH}$. In addition, the presence of organic matter and particular clay minerals also have a strong impacts on the color, both in terms of hue and intensity. ${ }^{3,16}$ However, the presence of these elements in sufficient quantity may be indicative of rocks with particular characteristics that do have an impact on color. The methodology applied in this work is intended to demonstrate that these characteristics could be acting as proxy indicators of specific elemental concentrations.
Previous studies show that the main coloration agent of clays was iron. ${ }^{17-22}$ In fact, iron oxides can color clay minerals either red or green or in various shades of orange and brown. The color most likely depends upon the relative abundance of the iron ion valence in the silicate (clay mineral in our case) structure, the specific bonding of these ions, and other factors. The reasons for coloration are not known completely, but it is certain that $\mathrm{Fe}^{2+}$ and $\mathrm{Fe}^{3+}$ ions make combinations with silica and aluminum to provide an orange to brown color for these materials. In the studied marls and phosphates samples, the high concentration of carbonates inhibits this iron effect by reducing the red $\left(a^{*}\right)$ and yellow $\left(b^{*}\right)$ shades, which leads to grayish materials. Therefore, despite the high iron content of magmatic rocks $\left(\mathrm{Fe}_{2} \mathrm{O}_{3}>10 \%\right)$, moderate $\mathrm{CaO}$ and $\mathrm{MgO}$ concentrations contained in these materials are sufficient to reduce the effect of iron ions (Figure 5). Previous studies have shown that $\mathrm{Ca}^{2+}$ ions play a dominant role in determining the color of materials and mineral phases in clays fired under reducing conditions, as they do in oxidizing atmospheres in presence of iron ions. ${ }^{23-26}$

The color variation between clay samples can also be explained by the transformation mechanism from ferrous iron to iron oxides controlled by the formation conditions of these rocks. ${ }^{27-29}$ Oxidation under surface conditions has a tendency to produce iron in the ferric state, most often the process takes iron out of the silicates and puts it
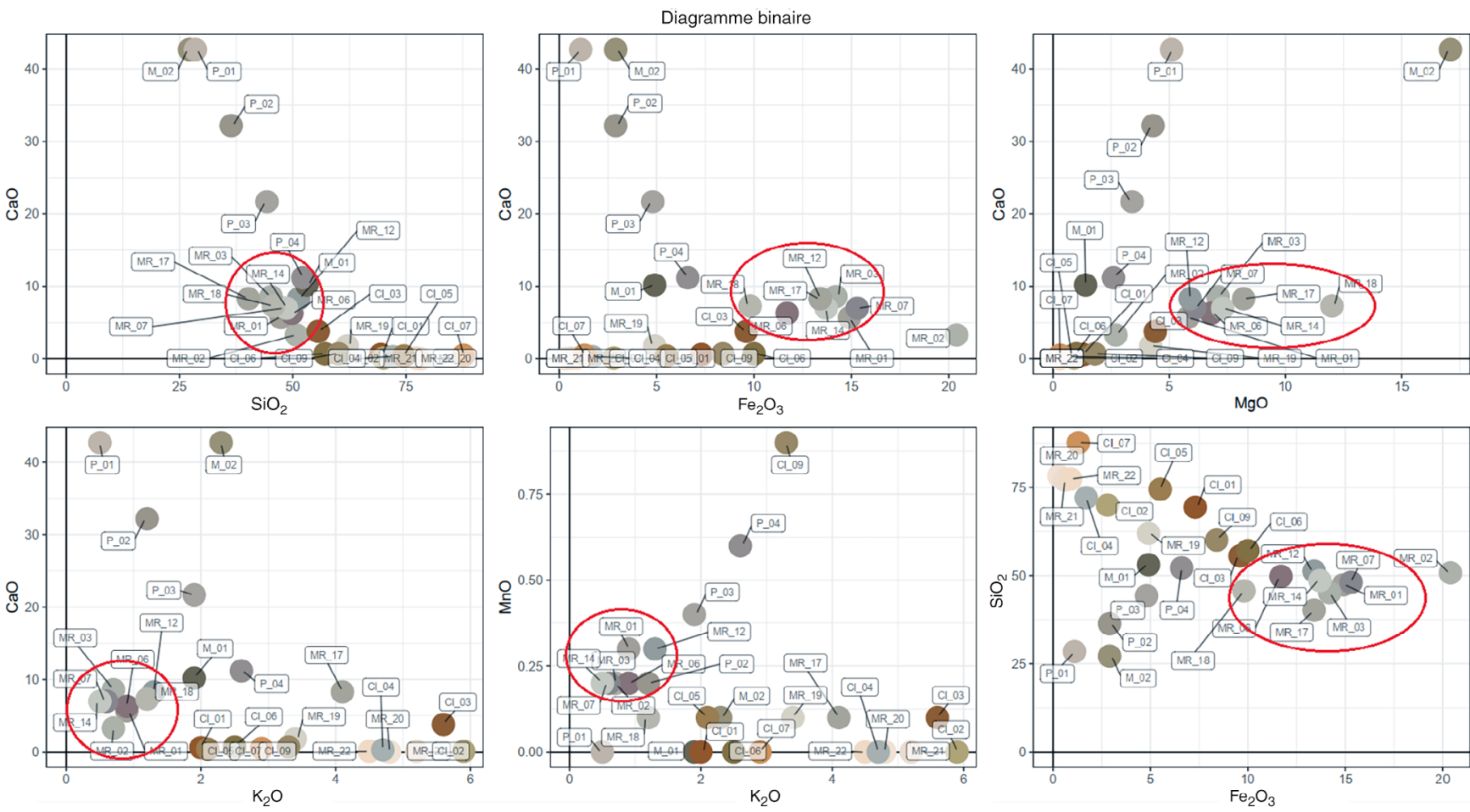

F I G U R E 5 Binary diagrams illustrating the relationship between color and chemical composition of the samples studied 
(A) Variables - PCA
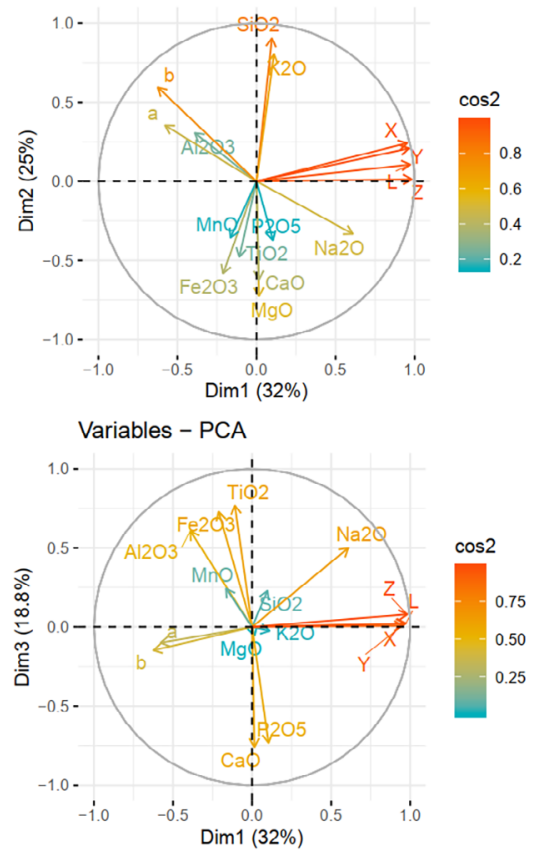

(B) Individuals - PCA
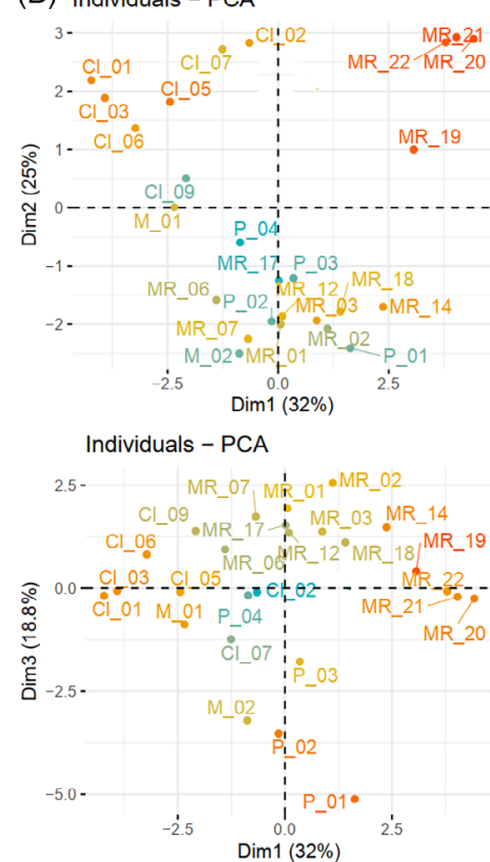
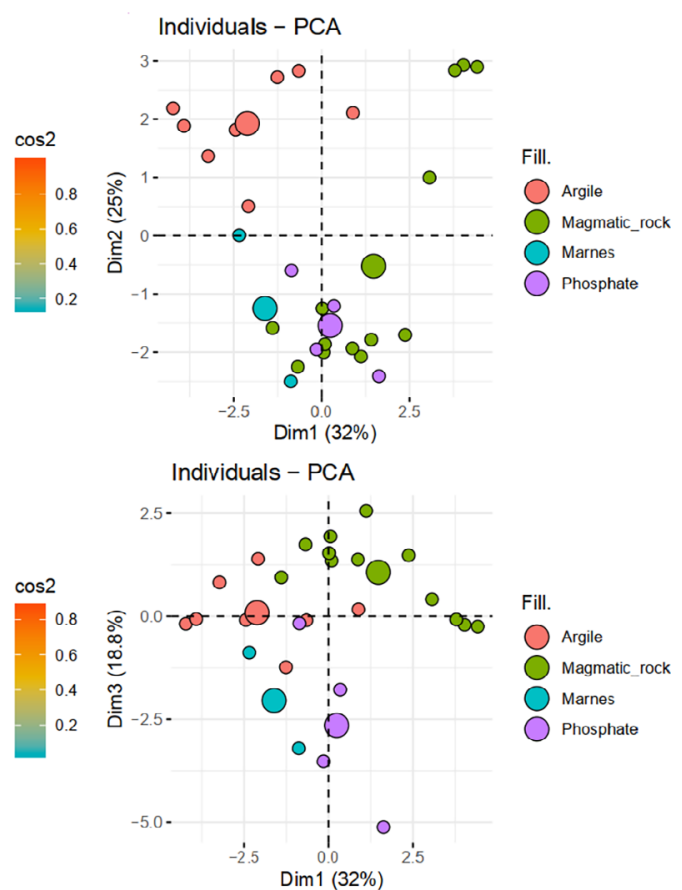

F I G U RE 6 Principal component analysis of variables (chemical composition and color parameters) and individuals

into an oxide phase which gives rocks with color tending to red (example of extremely weathered soils one finds only ferric iron and aluminum oxides and hydroxides). In the opposite sense, reducing conditions tend to increase the reduction of iron in the material and its introduction into silicate (clay mineral) phases. $^{30}$ Iron content can, however, lead to changes to earthy colors such as black, orange, and yellow in addition to red in a rock sample. ${ }^{31}$

Experimental studies have demonstrated how thermal alteration can change the color of rocks. ${ }^{32-34}$ Thermal alteration is often seen in reddening of the rock. ${ }^{21,35,36}$ Other color changes, such as rocks becoming grayer or blacker, have also been documented. ${ }^{37,38}$ In addition, it has been pointed out that some rocks do not display the expected signs of thermal alteration. ${ }^{39}$

Color changes in rocks can also be rooted in processes such as dispersed metal ions, a variety of defect structures created by radiation, and physical optics (see, for example, the overview by Fritsch and Rossman ${ }^{40-42}$ ).

When a rock is devoid of iron and calcium oxides (main coloration agents), case of MR20, MR21, and MR22 samples, high RGB and $L^{*}$ values are obtained, the color is different from other magmatic rocks and clays with a shade that shifts to light pink and white color.

PCA results also show a positive correlation between silica and potassium with $\mathrm{a}^{*}$ and $\mathrm{b}^{*}$ coordinates for clay materials (Figure 6). However, it remains difficult to find a significant correlation between chemical elements of magmatic rocks with color parameters. Results reveal that CIELAB color was found to be a slightly better overall predictor of material characteristics than RGB, but this is balanced against the ease of use of RGB when dealing with digital image color and visualization using computer equipment. The benefits of CIELAB over RGB are not therefore considered strong enough to argue for its use in deriving material chemical compositions instead of RGB.

The Munsell scale where values indicate the lightness of a color allows to discern groups of samples according to the color evidenced by the PCA (Figure 7). The scale of values goes from 0 for pure black to 10 for pure white. Black, white, and the grays have no Hue so they are called neutral colors. Colors that have a Hue are called "chromatic colors." This system is based on five basic color fields: R red, Y yellow, G green, B blue, P purple (between reds and blues) plus five intermediate fields. Each of the colors is given in 10 shades, and a shade is defined by an abbreviation and a number. For our samples, the values of Hue obtained vary between 2.5, 5, 7.5, and 10 (Table 1).

According to Musell scale, the classification of the colors is defined in the colorimetric space by the three fundamental quantities of the human visual perception, the hue, the value or lightness, and the chroma, which it defines as the degree of saturation, from gray to the most intense color.

The PCA shows a dispersion of the samples around these three values, three groups are distinguished. The 

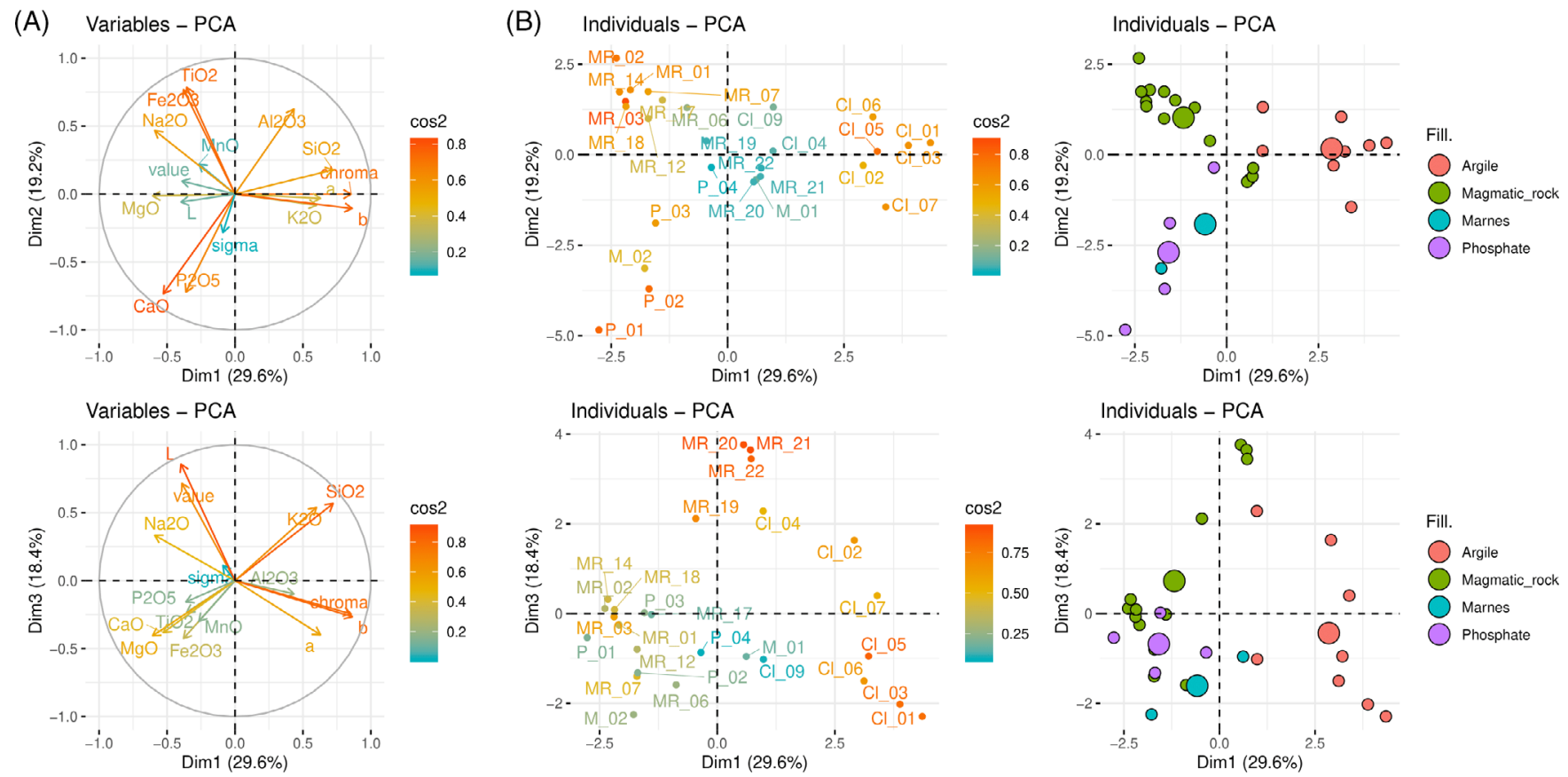

F I G U RE 7 Principal component analysis of variables with Munsell scale parameters

clay samples show an affinity with the chroma value, a* and $b^{*}$ parameters (Figure 7). However, the samples of phosphates and marls, rich in $\mathrm{P}_{2} \mathrm{O}_{5}$ and $\mathrm{CaO}$, are refined with the value of sigma. The magmatic rock samples form their own distinct group and show a positive correlation with the $\mathrm{L}^{*}$ parameter.

\section{5 | CONCLUSION}

This study examined the strength of using digital image parameters to evaluate color changes in rocks. This relatively cheap and accessible method was superior in identifying the distinction between magmatic and sedimentary rock samples based on color. A continuous colour change from light to dark shades has been observed and measured by spectrophotometry. The color most likely depends upon the relative abundance of the iron ions $\left(\mathrm{Fe}^{2+}\right.$ and $\left.\mathrm{Fe}^{3+}\right)$ in these rocks. However, the presence of carbonates in sufficient quantities reduces the reddish effect of iron and transforms the color into gray shades; the origin of this variation is due to the incorporation of iron ions in several calcium silicates. In soils, besides the chemical composition, previous studies have shown that organic matter, quartz, red color of hematite $\left(\alpha-\mathrm{Fe}_{2} \mathrm{O}_{3}\right)$, yellow color of goethite $(\alpha-\mathrm{FeOOH})$, calcite, and other carbonates may affect the colour of these rocks. ${ }^{3,43}$

The obtained results have important geological implications, they allow classification of rocks and estimation of the chemical composition from their colors, and this will enable to get a maximum of information about a rock using visual and imaging analysis only.

\section{ACKNOWLEDGMENTS}

The financial support is provided by the "Bilateral Cooperation Project Wallonie Bruxelles Maroc" (Grant 2.7) and by the PPR-CNRST Program (Grant PPR1/2015/63) that are all gratefully acknowledged. The first author acknowledges the financial support provided by Erasmus Plus.

\section{DATA AVAILABILITY STATEMENT}

The data that support the findings of this study are available from the corresponding author upon reasonable request.

\section{ORCID}

Mouhssin El Halim (D) https://orcid.org/0000-0001-72507052

Lahcen Daoudi (1) https://orcid.org/0000-0001-7550-4287 Abdelhafid El Alaoui El Fels (1) https://orcid.org/00000001-8083-5427

\section{REFERENCES}

[1] Osinski GR, Grieve RAF, Bleacher JE, Neish CD, Pilles EA, Tornabene LL. Igneous rocks formed by hypervelocity impact. J Volcanol Geotherm Res. 2018;353:25-54.

[2] Flemming BW. Geology, morphology and sedimentology of estuaries and coasts. In: Flemming BW, Hansom JD, eds. Treatise on Estuaries and Coasts, Vol. 3, Estuarine and Coastal Geology and Morphology. Amsterdam: Elsevier; 2011: 7-38. 
[3] Aitkenhead MJ, Dalgetty IA, Mullins CE, McDonald AJS, Strachan NJC. Weed and crop discrimination using image analysis and artificial intelligence methods. Comput Electron Agric. 2003;39:157-171.

[4] Gokay MK. Influence of natural weathering on rock mass colour. Madencilik. 2003;42(1):35-41.

[5] Hajpal M, Torok A. Mineralogical and colour changes of quartz sandstones by heat. Environ Geol. 2004;46:311-322. https:// doi.org/10.1007/s00254-004-1034-Z

[6] Baykan NA, Yilmaz N, Kansun G. Case study in effects of color spaces for mineral identification. Sci Res Essays. 2010; 5(11):1243-1253.

[7] Zhong S, Han Z, Du J. Relationships between the lithology of purple rocks and the pedogenesis of purple soils in the Sichuan Basin, China. Sci Rep. 2019;9:13272. https://doi.org/10. 1038/s41598-019-49687-9

[8] Christidis G, Makri P, Perdikatsis V. Influence of grinding on the structure and colour properties of talc, bentonite and calcite white fillers. Clay Miner. 2004;39(2):163-175. https://doi. org/10.1180/0009855043920128

[9] Krishna Murti GSR, Satyanarayana KVS. Influence of chemical characteristics in the development of soil colour. Geoderma. 1971;5(3):243-248.

[10] Davey BG, Russel JD, Wilson MJ. Iron oxide and clay minerals and their relation to colors of red and yellow podzolic soils near Sydney, Australia. Geoderma. 1975;14:125-138.

[11] Prieto B, Sanmartín P, Silva B, Martínez-Verdú F. Measuring the color of granite rocks: a proposed procedure. Color Res Appl. 2010;35(5):368-375.

[12] El Halim M, Daoudi L, El Alaoui El Fels A, Rebbouh L, El Ouahabi M, Fagel N. Non-destructive portable X-ray fluorescence (pXRF) method for the characterization of Islamic architectural ceramic: example of Saadian tombs and El Badi palace ceramics (Marrakech, Morocco). J Archaeol Sci Rep. 2020;32:102422. https://doi.org/10.1016/j.jasrep.2020.102422

[13] Boronkay G. Colour Conversion Centre, 2012. http://ccc. orgfree.com/

[14] Husson F, Josse J, Pagès J. Principal Component Methods Hierarchical Clustering - Partitional Clustering: Why Would We Need to Choose for Visualizing Data? . Agrocampus: Applied Mathematics Department; 2010:1-17.

[15] Fairchild MD. Color Appearance Models. Rochester, NY: John Wiley \& Sons Ltd, Munsell Color Science Laboratory Rochester Institute of Technology; 2005.

[16] Ferreira Costa JJ, Giasson E, Benedet da Silva E, Coblinski JA, Tiecher T. Use of color parameters in the grouping of soil samples produces more accurate predictions of soil texture and soil organic carbon. Comput Electron Agric. 2020;177:105710. https://doi.org/10.1016/j.compag.2020.105710

[17] Purdy B. Investigations Concerning the Thermal Alteration of Silica Minerals: An Archaeological Approach [PhD dissertation]. University of Florida; 1971.

[18] Nagano T, Nakashima S. Study of colors and degrees of weathering of granitic by visible diffuse reflectance spectroscopy rocks. Geochem J. 1989;23:75-83.

[19] Fiori C., Fabbri B., Donati G., \& Venturi I. Mineralogical composition of the clay bodies used in the Italian tile industry, Appl Clay Sci, 1989, Vol. 4, I. 5-6, pp. 461-473.

[20] Baccour H, Medhioub M, Jamoussi F, Mhiri T, Daoud A. Mineralogical evaluation and industrial applications of the Triassic clay deposits, southern Tunisia. Mater Charact. 2008;59:16131622.

[21] Homsey LK. The identification and prehistoric selection criteria of fire-cracked rock: an example from Dust Cave, Alabama. Southeast Archaeol. 2009;28:99-114.

[22] El Halim M., Daoudi L., El Ouahabi M., Amakrane J., \& Fagel N. Mineralogy and firing characteristics of clayey materials used for ceramic purposes from Sale region (Morocco), J Mater Environ Sci, 2018, Vol. 9, I. 8, pp. 2263-2273.

[23] Freeman IL. Mineralogy of ten British brick clays. Clay Miner Bull. 1964;5:474-486.

[24] West IM. Macrocell structure and enterlolithic facies in the Visean of Ireland. Geol Soc Yorkshire Proc. 1965;35:47-58.

[25] Maniatis Y., \& Tite M.S. Technological examination of Neolithic-Bronze Age pottery from Central and Southeast Europe and from the near east, J Archaeol Sci, 1981, Vol. 8, I. 1, pp. 59-76.

[26] Molera J, Pradell T, Vendrell-Saz M. The colours of Ca-rich ceramic pastes: origin and characterization. Appl Clay Sci. 1998;13:187-202.

[27] Velde B. Diagenetic clay mineral composition as a function of pressure, temperature, and chemical activity. $J$ Sediment Res. 1985;55(4):541-547. https://doi.org/10.1306/212F8724-2B2411D7-8648000102C1865D

[28] Boggs JS. Petrology of Sedimentary Rocks. 2nd ed. New York: Cambridge University Press; 2009:600.

[29] Dauphas N, Roskosz M, Alp EE, et al. Magma redox and structural controls on iron isotope variations in Earth's mantle and crust. Earth Planet Sci Lett. 2014;398:127-140.

[30] Velde B. The effect of chemical reduction on the stability of pyrophyllite and kaolinite in pelitic rocks. J Sediment Res. 1968;38(1):13-16.

[31] Prinsloo LC, van der Merwe EM, Wadley L. The thermal behaviour of silica varieties used for tool making in the Stone Age. J Therm Anal Calorim. 2018;131:1135-1145.

[32] Dumarçay G. Vedlegg 3: Preliminary analysis of thermal alterations process in rocks from Rena River area (Norway), by laboratory experiment. In: Stene K, ed. Steinalderundersøkelser ved Rena elv. Gråfjellprosjektet bind III; Fornminneseksjonen: Kulturhistorisk museum; 2010:567-574.

[33] Graesch AP, DiMare T, Schachner G, Schaepe DM, Dallen JJ. Thermally modified rock: the experimental study of 'fire cracked' byproducts of hot rock cooking. North Am Archaeol. 2014;35(2):167-200.

[34] Bentsen SE, Wurz S. Color me heated? A comparison of potential methods to quantify color change in thermally-altered rocks. J Field Archaeol. 2019;44:215-233. https://doi.org/10. 1080/00934690.2019.1591092

[35] House JH, Smith JW. Experiments in replication of fire cracked rock. In: Schiffer MB, House JH, eds. The Cache River Archaeological Project: An Experiment in Contract Archaeology; Arkansas Archeology Survey; 1975:75-80.

[36] Wilson DC, DeLyria DV. The experimental reduction of rock in a camas oven: towards an understanding of the behavioral significance of fire-cracked rock. Archaeology in Washington VII, 1999:81-89.

[37] Backhouse PN, Johnson E. Where were the hearths: an experimental investigation of the archaeological signature of prehistoric fire technology in the alluvial gravels of the Southern Plains. J Archaeol Sci. 2007;34(9):1367-1378. 
[38] Moody D. Thermal alteration of quartzite from Spanish Diggings, Wyoming - a pre-historic quarry. Transactions of the Nebraska Academy of Sciences and Affiliated Societies Paper 409, 1976.

[39] Rapp GJ, Balescu S, Lamothe M. The identification of granitic fire-cracked rocks using luminescence of alkali feldspars. Am Antiq. 1999;64(1):71-78.

[40] Fritsch E, Rossman GR. An update on color in gems. Part 1: introduction and colors caused by dispersed metal ions. Gems Gemol. 1987;23(3):126-139.

[41] Fritsch E, Rossman GR. An update on color in gems. Part 2: colors involving multiple atoms and color centers. Gems Gemol. 1988;24(1):3-15.

[42] Fritsch E, Rossman GR. An update on color in gems. Part 3: colors caused by band gaps and physical phenomena. Gems Gemol. 1988;24(2):81-102.

[43] Aitkenhead MJ, Coull M, Towers W, Hudson G, Black HIJ. Prediction of soil characteristics and colour using data from the National Soils Inventory of Scotland. Geoderma. 2013;200-201:99-107.

\section{AUTHOR BIOGRAPHIES}

Mouhssin El Halim is a $\mathrm{PhD}$ graduate in Geosciences and Geo-materials at the Faculty of Sciences Semlalia of Marrakech, University Cadi Ayyad Morocco, and at the Faculty of Sciences of Liege, Belgium. He is a supervisor of the Geo-Resources, Geo-Environment and Civil Engineering Laboratory at the Faculty of Science and Technology in
Marrakech, Morocco. He is a specialist in materials science, conservation, and restoration of construction materials, and physico-chemistry of geo-materials.

Lahcen Daoudi has been Professor of Geology, Geochemistry and Hydrology in the Department of Geology at the Faculty of Science and Technology of Marrakech, Morocco since 1991. Also, he is the Director of the Geo-Resources, Geo-Environment and Civil Engineering Laboratory (L3G) in the Faculty of Science and Technology of Marrakech, specializing in sedimentology, pedology, and mineralogy.

Abdelhafid El Alaoui El Fels is a $\mathrm{PhD}$ graduate in data analysis, geo-informatics and modeling of geological and hydro-geological events in the Faculty of Sciences Semlalia, Cadi Ayyad University of Marrakech, Morocco. He is a specialist in data processing, geo-statistics, and remote sensing.

How to cite this article: El Halim M, Daoudi L, El Alaoui El Fels A. How elemental composition influences the color of igneous and sedimentary rocks: Case of the High Atlas rocks of Morocco. Color Res Appl. 2021;1-11. doi:10.1002/col.22735 